\title{
Produção de biossurfactante por Lysinibacillus sp. e Bacillus sp. a partir de diferentes óleos como fonte de carbono
}

\author{
Production of biosurfactant by Lysinibacillus sp. \\ and Bacillus sp. from different oils \\ as carbon source
}

\begin{abstract}
Grazieny Aparecida Mendes de Almeida ${ }^{1}$, Maria dos Remédios Araújo Vieira Neta ${ }^{1}$, Gabriela Fiori da Silva ${ }^{1}$, Pierre Ferreira do Prado ${ }^{2}$
\end{abstract} Mônica Aparecida de Almeida ${ }^{1}$, Iolanda Cristina Silveira Duarte ${ }^{1}$

\footnotetext{
${ }^{1}$ Departamento de Biologia, Universidade Federal de São Carlos, campus Sorocaba, Rodovia João Leme dos Santos (SP264), km 110, 18052-780, Sorocaba, SP, Brasil.

${ }^{2}$ Universidade Estadual Paulista, campus Sorocaba, Avenida Três de Março, no 511 no Alto da Boa Vista, Sorocaba, SP, Brasil.

e-mail: iolanda@ufscar.br,p.prado@unesp.br
}

\begin{abstract}
RESUMO
Biossurfactantes são moléculas multifuncionais produzidas por microrganismos e podem apresentar vantagens em relação aos surfactantes sintéticos, como baixa toxicidade, alta biodegradabilidade, maior redução da tensão superficial e alta diversidade química. No entanto, a produção em escala comercial ainda é escassa devido ao elevado custo dos substratos utilizados. Portanto, no presente trabalho foi avaliada a produção de biossurfactantes utilizando diferentes óleos como fonte de carbono, como óleo de soja, óleo de fritura, óleo diesel, óleo lubrificante novo e usado, a partir de dois gêneros de bactérias isoladas de lodo indústria de cosméticos e solo contaminado com óleo diesel, Lysinibacillus sp. e Bacillus sp. respectivamente. Estas foram identificadas por sequenciamento do fragmento do gene RNAr 16S e mantidas sob refrigeração a $4{ }^{\circ} \mathrm{C}$ em tubos de ensaio, com ágar triptona de soja. Os ensaios de produção foram realizados sob agitação de $200 \mathrm{rpm}$ a $30{ }^{\circ} \mathrm{C}$ com duração de 7 dias. A produção de biossurfactante foi analisada pela atividade emulsificante, índice emulsificação e por colapso da gota. As bactérias utilizadas produziram biossurfactante em todos os tipos de óleos testados. O óleo de soja mostrou-se o melhor substrato para produção de biossurfactante a partir do Lysinibacillus sp. e Bacillus sp. com índice de emulsificação de $50 \%$ e 46,63\%, respectivamente.
\end{abstract}

Palavras-chave: emulsificantes; bactérias; fontes alternativas; fermentação.

\begin{abstract}
Biosurfactants are multifunctional molecules produced by microorganisms and have some advantages compared to synthetic surfactants, such as low toxicity, high biodegradability ,improved tensoactivity and chemical diversity. However, commercial scale production is not viable due to the high cost of the substrates used. Therefore, in the present work we evaluated the production of biosurfactants using different oils as carbon source, such as soybean oil, frying oil, diesel oil, new and used lubricating oil, from two genera of bacteria isolated from sludge cosmetics industry and soil contaminated with diesel oil, Lysinibacillus sp. and Bacillus sp. respectively. These were identified by sequencing the 16S rRNA gene fragment and kept under refrigeration at $4{ }^{\circ} \mathrm{C}$ in test tubes with tryptone soy agar. The production was carried out under agitation at $200 \mathrm{rpm}$ at $30{ }^{\circ} \mathrm{C}$ for 7 days. The biosurfactant production was analyzed by emulsifying activity, emulsification index and drop collapse. The bacteria used produced biosurfactant in all types of oils tested. Soybean oil was the best substrate for the production of biosurfactant from Lysinibacillus sp. and Bacillus sp. with an emulsification index of $50 \%$ and $46.63 \%$, respectively.
\end{abstract}


Keywords: Emulsifiers; bacterium; alternative sources; fermentation.

\section{INTRODUÇÃO}

Biossurfactantes ou biotensoativos são surfactantes de origem microbiana, produzidos por bactérias, leveduras e fungos $[1,2]$. São compostos anfipáticos, contendo grupos hidrofóbicos (apolares) e hidrofílicos (polares) [3], que reduzem a tensão superficial ou interfacial entre duas fases líquidas [4, 5]. Essas moléculas orgânicas complexas podem apresentar propriedades, composição química e tamanhos moleculares diversos [6], sendo assim, classificados com base na estrutura da biomolécula e espécie produtora [1, 7].

O gênero Bacillus é um dos mais estudados para produção de lipopeptídios [3, 8]. As espécies pertencentes a esse gênero produzem diferentes tipos desse biossurfactante como bacilomicinas [9], micosubtilionas [10], fengicinas [11], iturinas e surfactina [12], sendo este último, considerado como um dos mais interessantes biossurfactantes, pois apresentam citotoxicidade contra vários tipos de câncer, inibindo o crescimento celular, o ciclo celular, apoptose e interrupção da metástase, assim evitando a progressão da doença [13]. Além disso, a surfactina pode ser usada como agente de controle biológico de patógenos, devido as suas propriedades antibacterianas e antivirais [14].

Espécies do gênero Lysinibacillus também apresentam potencial para a produção de lipopeptídios, como o Lysinibacillus chungkukjangi, a qual produz lipopetídeos que tiveram suas propriedades recentemente descobertas, com possibilidade de aplicação desse biossurfactante em vários ramos da indústria tais como: alimentício, farmacêutico e recuperação de petróleo [15].

A maioria dos surfactantes utilizados atualmente, provêm da indústria petroquímica, entretanto com os recorrentes problemas ambientais [16], a demanda por surfactantes biológicos tem aumentado. O uso de biossurfactantes como alternativas aos surfactantes sintéticos foi impulsionada pelo rápido progresso da biotecnologia $[17,18]$ e também por serem compostos naturais que oferecem uma série de vantagens sobre os surfactantes sintéticos [5, 19], como o potencial de biodegradabilidade, baixa toxicidade, solubilização de hidrocarbonetos, estabilidade térmica [20], ação antimicrobiana [7], antibacteriana [21], antifúngica [22], antiviral [14] podendo ser sintetizados a partir de matérias-primas de baixo custo, gerando uma economia em torno de $50 \%$ na produção final de biossurfactantes [5].

As propriedades e características dos biossurfactantes fazem com que este seja considerado uma molécula versátil podendo ser aplicado na indústria agrícola, cosmética e de detergentes [23], na biorremediação e biodegradação, entre muitas outras [19, 24]. Porém o alto custo para sua obtenção impede sua viabilidade para produção e aplicação em larga escala. Como estratégia para a redução dos custos da produção de biossurfactante, os subprodutos e os resíduos da agroindústria têm sido avaliados como fontes de carbono alternativas [5], favorecendo, também, a minimização do impacto ambiental causado pelo descarte inadequado desses resíduos no ambiente [25].

Assim, com o intuito de prospectar a produção de biossurfactante com baixo custo, o presente trabalho teve como objetivo avaliar as bactérias Lysinibacillus sp. e Bacillus sp. utilizando óleo de soja, óleo de fritura, óleo diesel, óleo lubrificante novo e usado como fontes de carbono para produção de biossurfactante.

\section{MATERIAIS E MÉTODOS}

A metodologia foi desenvolvida de acordo com o fluxograma operacional representado na Figura 1. 


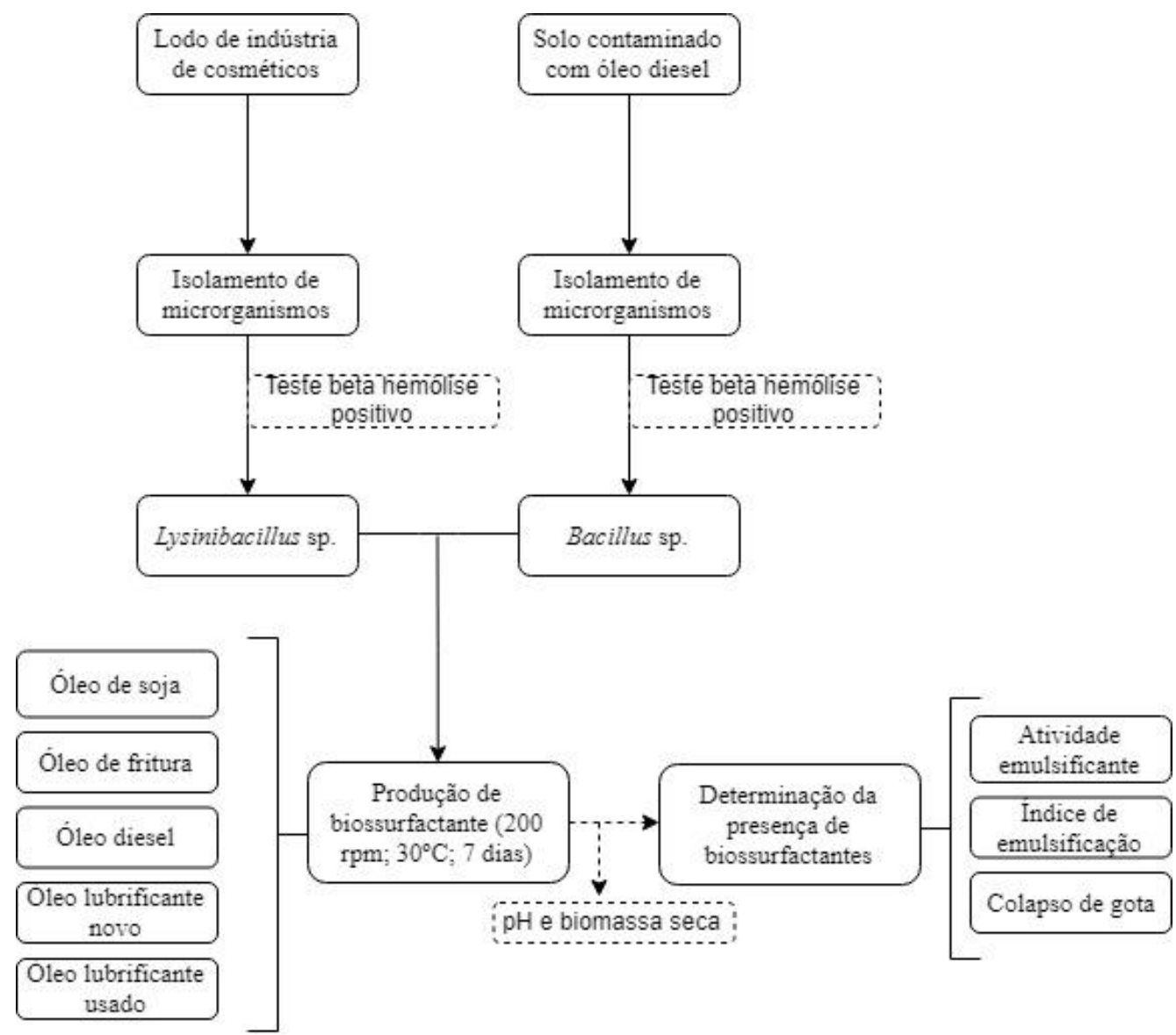

Figura 1: Fluxograma operacional.

\subsection{Microrganismos}

Os microrganismos utilizados foram: Lysinibacillus sp., isolado de amostras de lodo do reservatório de uma indústria de insumos cosméticos, situada na cidade de Sorocaba e Bacillus sp. isolado de solo contaminado com óleo diesel, obtido na cidade de Tatuí, ambas as cidades estão situadas em São Paulo, Brasil. As bactérias foram avaliadas por testes de beta hemólise e o resultado foi positivo para produção de biossurfactantes.

A identificação foi realizada por sequenciamento do fragmento do gene RNAr 16S. A metodologia consistiu na extração do DNA genômico diretamente das culturas, segundo protocolo descrito por VAN SOOLINGER et al. [26]. Os oligonucleotídeos sintéticos utilizados para a reação de PCR foram p10f e p1100r, homólogos às extremidades conservadas do gene RNAr $16 \mathrm{~S}$ de bactérias. Os produtos das amplificações foram purificados e submetidos diretamente ao sequenciamento usando o sequenciador automático ABI3500XL Series (Applied Biosystems). Os primers utilizados para o sequenciamento foram p10f e p1100r. As sequências obtidas foram comparadas com as bases de dados do Genbank e do RDP.

\subsection{Produção do inóculo}

A padronização do inóculo para os ensaios de produção de biossurfactantes foi realizada em solução salina $(0,9 \%)$ e a absorbância foi verificada em espectrofotômetro através da turbidez observada em um comprimento de onda de $550 \mathrm{~nm}$, que correspondeu a $1,5 \times 10^{8} \mathrm{UFC} / \mathrm{mL}$ [27].

\subsection{Produção de biossurfactante}

O meio de produção de biossurfactante (controle) foi composto por (em g/L): extrato de levedura $(0,2)$, peptona (1), glicose (5), $\mathrm{NaNO}_{3}(5), \mathrm{K}_{2} \mathrm{HPO}_{4}(1), \mathrm{MgSO}_{4}(0,5), \mathrm{FeSO}_{4} \cdot 7 \mathrm{H}_{2} \mathrm{O}(0,01), \mathrm{KCl}(0,03), \mathrm{CaCl}_{2}(0,02)$, $\mathrm{KH}_{2} \mathrm{PO}_{4}(0,8)$ e $1 \%$ de óleo. Os óleos testados como fonte de carbono foram: óleo de soja, óleo de fritura, óleo diesel, óleo lubrificante de motor novo e óleo lubrificante de motor usado. O meio foi esterilizado em autoclave a $121^{\circ} \mathrm{C}$ por $15 \mathrm{~min}$. A fermentação foi realizada em frascos reagente de $250 \mathrm{~mL}$ contendo 49,0 
$\mathrm{mL}$ do meio de cultura e $1 \mathrm{~mL}$ do inóculo. Após a inoculação, os frascos foram incubados a $30{ }^{\circ} \mathrm{C}$ e $200 \mathrm{rpm}$, durante 7 dias [28].

\subsection{MÉTODOS ANALÍTICOS}

\subsubsection{Determinação da presença de biossurfactante}

Amostras do meio de cultura fermentado foram centrifugadas a $4000 \mathrm{rpm}$ por $20 \mathrm{~min}$ a $20^{\circ} \mathrm{C}$, para remoção das células bacterianas. $\mathrm{O}$ sobrenadante foi submetido às análises de atividade emulsificante, índice de emulsificação e teste de colapso de gota.

\subsubsection{Atividade emulsificante e Índice de emulsificação (\%)}

A atividade emulsificante foi determinada a partir de $3,5 \mathrm{~mL}$ do sobrenadante com adição de $2 \mathrm{~mL}$ de tolueno e, após agitação em vortex, foi realizada a leitura da densidade óptica em espectrofotômetro a 540 $\mathrm{nm}$ [29].

A determinação do índice de emulsificação foi realizada a partir da mesma mistura de sobrenadante e tolueno, mantida em repouso por $24 \mathrm{~h}$ conforme o método descrito por BICCA et al. [30].

Amostragens do sobrenadante foram realizadas no tempo inicial e após $24 \mathrm{~h}$ para identificar a estabilidade da emulsão. O índice de emulsificação $\left(E_{24}\right)$ foi calculado de acordo com a Equação 1 .

Onde: $\mathrm{I} \%=$ índice de emulsão $(\%) ; \mathrm{A}_{\text {emulsão }}=$ altura da camada emulsão $(\mathrm{cm}) ; \mathrm{A}_{\text {total }}=$ altura total $(\mathrm{cm})$.

$$
\mathrm{I} \%=\frac{A_{\text {emulsão }}}{A_{\text {total }}} \times 100
$$

\subsubsection{Colapso da gota}

Para determinar o colapso de gota utilizou-se microplacas de 96 poços rasos, untados com $2 \mu \mathrm{L}$ de óleo de motor $10 \mathrm{~W}-40$, mantidas em repouso por $24 \mathrm{~h}$. Após o repouso $5 \mu \mathrm{L}$ do sobrenadante foram transferidos para cada um dos poços e o espalhamento das gotas foi avaliado após $2 \mathrm{~min}$. O resultado foi considerado positivo quando visualmente se inferiu o espalhamento da gota [31].

\subsubsection{Biomassa Seca}

Ao final dos ensaios de produção, foram centrifugados $15 \mathrm{~mL}$ da cultura (4000 rpm, 20 min a $20^{\circ} \mathrm{C}$ ), o precipitado formado foi retirado e colocado em placas de Petri (previamente pesadas) e levadas a estufa a $105^{\circ} \mathrm{C}$ e pesadas após $24 \mathrm{~h}$ ou até peso constante.

\subsubsection{Determinação do $\mathrm{pH}$}

Determinação do pH foi realizada no início e no final da fermentação, através de leitura direta em phmetro digital.

\section{RESULTADOS}

O maior índice de emulsificação foi o obtido com o óleo de soja como fonte de carbono, enquanto que com o óleo lubrificante usado foi observado o menor índice (Figura 2), com os demais substratos o índice de emulsificação para o Bacillus sp. variou entre 44 a $46 \%$, e de 30 a $50 \%$ para o Lysinibacillus sp. 


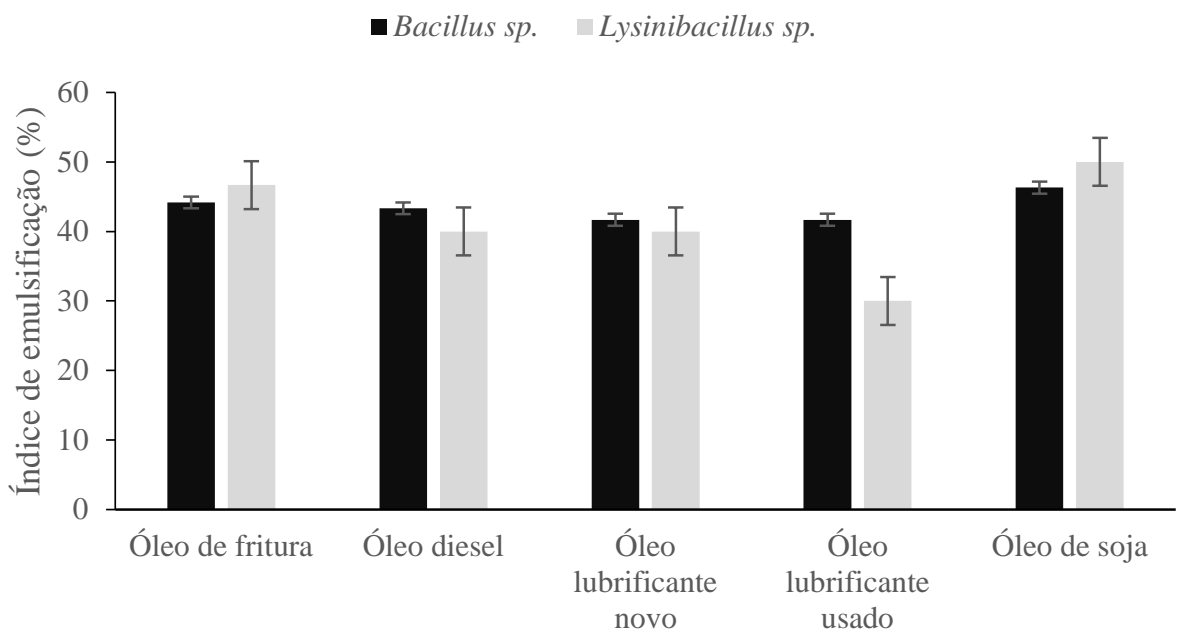

Fonte de carbono

Figura 2: Índices de emulsificação (\%) obtidos com as diferentes fontes de carbono.

A quantificação de biomassa seca bacteriana proveniente das cepas Bacillus sp. e Lysinibacillus sp. Esta apresentada na Tabela 1. Verificou-se que o caldo proveniente da fermentação com Lysinibacillus sp. e o óleo de soja como fonte de carbono, apresentou biomassa seca de 1,4 mg/L e índice de emulsificação em $50 \%$, em cultivo com óleo lubrificante usado foi de $330,0 \mathrm{mg} / \mathrm{L}$ e o índice de emulsificação de $30 \%$. Para o Bacillus sp. a biomassa seca foi de $70,0 \mathrm{mg} / \mathrm{L}$ proveniente de óleo de soja e de $50,0 \mathrm{mg} / \mathrm{L}$ para óleo lubrificante usado com índices de emulsificação em torno de $40 \%$.

A atividade emulsificante do Bacillus sp e Lysinibacillus sp. esta apresentada na Tabela 2,onde observou-se que o máximo de atividade foi de 1,03 por Bacillus sp. e 0,761 com Lysinibacillus sp. Para ambos os gêneros a fermentação com óleo lubrificante novo apresentaram as menores atividades emulsificantes $(0,057$ e 0,104$)$.

$\mathrm{Na}$ análise conjunta dos dados verificou-se que o óleo de soja, seguido de óleo de fritura foram as melhores fontes de carbono para produção de biossurfactante utilizando a cepa de Lysinibacillus sp.

Tabela 1: Biomassa seca (mg/L) do precipitado das bactérias Bacillus sp. e Lysinibacillus sp. nas diferentes fontes de carbono.

\begin{tabular}{c|c|c|c|c|c}
\hline MICRORGANISMO & $\begin{array}{c}\text { ÓLEO } \\
\text { DE SOJA }\end{array}$ & $\begin{array}{c}\text { ÓLEO DE } \\
\text { FRITURA }\end{array}$ & $\begin{array}{c}\text { ÓLEO } \\
\text { DIESEL }\end{array}$ & $\begin{array}{c}\text { ÓLEO } \\
\text { LUBRIFICANTE } \\
\text { NOVO }\end{array}$ & $\begin{array}{c}\text { ÓLEO } \\
\text { LUBRIFICANTE } \\
\text { USADO }\end{array}$ \\
\hline Bacillus sp. & 1,6 & 130,0 & 70,0 & 310,0 & 50,0 \\
\hline Lysinibacillus sp. & 1,4 & 200,0 & 70,0 & 120,0 & 330,0 \\
\hline
\end{tabular}

Tabela 2: Atividade emulsificante (\%) do sobrenadante livre de células

\begin{tabular}{c|c|c|c|c|c}
\hline MICRORGANISMO & $\begin{array}{c}\text { ÓLEO } \\
\text { DE SOJA }\end{array}$ & $\begin{array}{c}\text { ÓLEO } \\
\text { DE FRITURA }\end{array}$ & $\begin{array}{c}\text { ÓLEO } \\
\text { DIESEL }\end{array}$ & $\begin{array}{c}\text { ÓLEO } \\
\text { LUBRIFICANTE } \\
\text { NOVO }\end{array}$ & $\begin{array}{c}\text { ÓLEO } \\
\text { LUBRIFICANTE } \\
\text { USADO }\end{array}$ \\
\hline Bacillus sp. & 0,37 & 0,37 & 1,03 & 0,057 & 0,221 \\
\hline Lysinibacillus sp. & 0,761 & 0,243 & 0,741 & 0,104 & 0,146 \\
\hline
\end{tabular}


O biossurfactante produzido por Bacillus sp. e Lysinibacillus sp. em todos os óleos testaram positivo para o colapso de gota e a partir do resultado dessa análise qualitativa inferiu-se a propriedade tensoativa.

A determinação do $\mathrm{pH}$ foi realizada em duplicata após cada período de fermentação. Nos valores do pH do sobrenadante proveniente da fermentação dos meios de cultura em diferentes fontes de carbono, verificou-se que houve variação para os cinco substratos (Tabela 3).

Tabela 3: Medidas de $\mathrm{pH}$ ao final das fermentações de Bacillus sp. e Lysinibacillus sp. em cada fonte de carbono.

\begin{tabular}{c|c|c|c|c|c}
\hline MICRORGANISMO & $\begin{array}{c}\text { ÓLEO } \\
\text { DE SOJA }\end{array}$ & $\begin{array}{c}\text { ÓLEO DE } \\
\text { FRITURA }\end{array}$ & $\begin{array}{c}\text { ÓLEO } \\
\text { DIESEL }\end{array}$ & $\begin{array}{c}\text { ÓLEO } \\
\text { LUBRIFICANTE } \\
\text { NOVO }\end{array}$ & $\begin{array}{c}\text { ÓLEO } \\
\text { LUBRIFICANTE } \\
\text { USADO }\end{array}$ \\
\hline Bacillus sp. & 7,4 & 6,7 & 8,2 & 7,9 & 7,5 \\
\hline Lysinibacillus $\mathrm{sp}$. & 6,0 & 5,6 & 6,1 & 7,9 & 7,9 \\
\hline
\end{tabular}

$\mathrm{O}$ menor $\mathrm{pH}$ foi observado no ensaio com óleo de fritura. $\mathrm{O}$ pH das fermentações utilizando óleo de soja como fonte de carbono, que apresentou melhor atividade emulsificante, variou entre as espécies estudadas. $\mathrm{O}$ pH da fermentação com óleo diesel mostrou uma leve alcalinização e o pH do óleo de fritura apresentou uma leve acidez em relação as demais fontes de carbono.

\section{DISCUSSÃO}

Os diferentes óleos avaliados neste trabalho podem ser usados como substratos para a produção de biossurfactante por Lysinibacillus sp. e Bacillus sp. e consequentemente reduzir os custos da produção. De acordo com a literatura, isolados que apresentam índice de emulsificação a partir de $40 \%$ são promissores para produção de biossurfactantes, pois a propriedade de interesse do biossurfactante é sua capacidade de emulsionar líquidos não miscíveis e formar emulsões estáveis [32].

Entre as cinco fontes de óleos testadas, para produção de biossurfactante pelos isolados de Lysinibacillus sp. e Bacillus sp. o óleo de soja destacou-se com o maior índice de emulsificação, provavelmente esse resultado foi devido a estruturas orgânicas simples tais como ácidos graxos, cuja cadeia contém 8 a 20 átomos de carbono, que são facilmente metabolizáveis [33].

A produção de biossurfactante por Lysinibacillus sp. utilizando o óleo lubrificante usado apresentou o menor índice de emulsificação. Neste presente estudo não foi determinado a presença de metais neste óleo, entretanto, esse substrato normalmente apresenta concentração elevada de metais, que podem afetar os microrganismos [34]. De acordo com SADLER e TRUDINGER [35] dependendo da concentração de metais os microrganismos são afetados de diferentes formas causando alterações morfológicas e bioquímicas, podendo inibir o crescimento microbiano ou até mesmo causar a morte microbiana. Embora a concentração de metais neste óleo seja superior ao encontrado no óleo lubrificante novo, este substrato é muito estudado como fonte de carbono para distintas espécies bacterianas [36], pois apesar dos metais o óleo lubrificante usado apresenta em sua composição hidrocarbonetos [32], o óleo diesel também apresenta hidrocarbonetos em sua composição, sendo bastante relatado para prospecção de biossurfactante [37, 38].

A presença de hidrocarbonetos nos substratos é importante, pois eles estão envolvidos na síntese dos grupos hidrofóbicos e hidrofílicos das moléculas de biossurfactante. DESAI e BANAT [32] relataram que a síntese das porções hidrofóbicas e hidrofílicas, ocorre por duas vias metabólicas primárias usando hidrocarbonetos e carboidratos, respectivamente. Diversos conjuntos específicos de enzimas reguladoras estão envolvidos na síntese das duas porções das moléculas de biossurfactante. Há diferentes possibilidades para a síntese das porções hidrofóbicas e hidrofílicas das moléculas biossurfactante e seu acoplamento: (1) as porções hidrofílicas e hidrofóbicas são sintetizadas por duas vias independentes; (2) a porção hidrofílica é sintetizada enquanto a síntese da porção hidrofóbica é induzida pelo substrato; (3) a porção hidrofóbica é sintetizada, enquanto a síntese da porção hidrofílica é dependente do substrato; e (4) a síntese de ambas as porções hidrofóbicas e hidrofílicas é dependente do substrato.

MNIF et al. [39] verificaram a produção de biossurfactante para Lysinibacillus fusiformis utilizando como substrato o petróleo bruto a $1 \%$ e obtiveram um índice de emulsificação de $72 \%$, e mostraram que essa bactéria pode ser utilizada para biorremediação em locais contaminados com hidrocarbonetos. SILVA et al. [40] relataram que o biossurfactante produzido por Pseudomonas aeruginosa apresentou um valor de emulsão de $53,7 \%$ e 50,2\% para o óleo diesel e óleo de motor, respectivamente. 
A composição do óleo de cozinha é alterada depois do uso para fritura. O processo de fritura altera a concentração de ácidos graxos poliinsaturados, aumentando os ácidos graxos saturados e monoinsaturados [41], com isso este óleo pode conter $30 \%$ de compostos polares, entretanto este valor pode mudar dependendo da variedade de alimentos, do tipo de fritura e do número de vezes em que este foi utilizado [42].

O índice de emulsificação para o óleo de fritura obtido a partir do Bacillus sp. no presente estudo foi semelhante ao mostrado por OLIVEIRA et al. [43] que ao utilizarem o mesmo substrato como fonte de carbono para Bacillus pulimus, produziram biossurfactante e obtiveram um índice de emulsificação que variou de $45 \%$ a $50 \%$. Os autores adicionaram ao meio de sais minerais diferentes concentrações do óleo de fritura (1\% a 5\%). Comumente as espécies pertencentes ao gênero Bacillus são bastantes estudadas e relatadas como produtoras de diferentes tipos biossurfactante, sendo a surfactina o principal lipopeptídio sintetizado [13].

É notório que existe uma grande variabilidade em relação ao índice de emulsificação, pois o tipo de biossurfactante produzido bem como as diferentes fontes de carbono testadas podem alterar a estrutura dos biossurfactantes e com isso influenciarem nas propriedades emulsificantes [44]. Além disso, a emulsão de diferentes hidrocarbonetos ocorre de distintas formas [45]. Com base nesse contexto pode-se justificar o fato de uma mesma linhagem de Bacillus sp. ou Lysinibacillus sp. mostraram diferentes índices de emulsificação devido ao uso de diferentes óleos como fonte de carbono.

A concentração do substrato ou a adição de suplementos ao meio podem influenciar na atividade emulsificante do biossurfactante, esse fato foi relatado por KIM et al. [46] que mostraram que a atividade emulsificante do Emulsan pode ser modificada com a suplementação de ácidos graxos, atingindo uma maior atividade emulsificante $(2,44$ a $600 \mathrm{~nm})$. O Emulsan é um biossurfactante polimérico e é sintetizado por Acinetobacter calcoaceticus, sendo reconhecido por sua capacidade em estabilizar emulsões do tipo óleo/água [47]. KITAMOTO et al. [48] utilizaram lipídios de monosileritritol produzido por Pseudozyma (Candida antarctica) a partir de óleos vegetais para produzir biossurfactante e obtiveram uma atividade emulsificante de 1,5 e 2,0 a $620 \mathrm{~nm}$.

Embora a produção de biossurfactante seja comumente relatada como dependente do crescimento celular [42], no presente estudo não houve essa relação, pois, alguns fatores como a concentração do substrato, pH e a composição do meio de cultivo podem interferir de forma a inibir ou aumentar a concentração do biossurfactante e o crescimento celular [49].

A redução no $\mathrm{pH}$ foi observada em alguns substratos avaliados e tal fato possivelmente ocorreu devido à produção de metabólitos secundários pelas bactérias, que acidificam o meio durante o processo de fermentação [50]. O pH também pode ter influenciado na produção de biossurfactante, pois em pH ácido ou pH alcalino demais pode ocorrer um baixo nível de produção de biossurfactante [36].

\section{CONCLUSÕES}

Os isolados Lysnibacillus sp. e Bacillus sp. foram capazes de produzir biossurfactantes a partir de diferentes óleos como fonte de carbono. O óleo de soja foi o substrato que apresentou os melhores resultados. O biossurfcatante produzido pode ser aplicado como agente emulsificante e surfactante. Este trabalho alinha-se ao esforço de prospecção de diversos resíduos e/ou subprodutos a serem utilizados como fonte de carbono, de baixo custo, na produção de moléculas de interesse biotecnológico.

\section{AGRADECIMENTOS}

Ao programa de Pós-Graduação em Biotecnologia e Monitoramento Ambiental e ao Programa de PósGraduação em Planejamento e Uso de Recursos Renováveis (PPGPur) da UFSCar.

\section{BIBLIOGRAFIA}

[1] BANAT, I.M., FRANZETTI, A., GANDOLFI, I., et al., "Microbial biosurfactants production, applications and future potential", Applied Microbiology Biotechnology, v. 87, n. 2, pp. 427-444, Abr. 2010.

[2] SANTOS, A.P.P., SILVA, M.D.S., COSTA, E.V.L, et al., "Production and characterization of a biosurfactant produced by Streptomyces sp. DPUA 1559 isolated from lichens of the Amazon region”, Brazilian Journal of Medical and Biological Research, v. 51, n. 2, pp. 1-10, Abr. 2018.

[3] OTZEN, D.E. "Biosurfactants and surfactants interacting with membranes and proteins : same but different?", Biochimica et Biophysica Acta, v. 1859, n. 4, pp. 639-649, Abr. 2017. 
[4] ABALOS, A. PINAZO, A., INFANTE, M.R., et al., "Physicochemical and antimicrobial properties of new rhamnolipids produced by Pseudomonas aeruginosa AT10 from soybean oil refinery wastes", Langmuir, v.17, n.5. pp. 1367-1371, Fev. 2001.

[5] MAKKAR, R.S., CAMEOTRA, S.S. "Biosurfactant production by microorganisms on unconventional carbon sources”, Institute of Microbiology Tecnology, v. 2, n. 2, pp. 237-238, Abr. 1999.

[6] GEYS, R., SOETAERT, W., VAN BOGAERT, I. "Biotechnological opportunities in biosurfactant production”, Current Opinion in Biotechnology, v. 30, pp. 66-72, Dez. 2014.

[7] BAINDARA, P., MANDAL, S.M., CHAWLA, N., et al., "Characterization of two antimicrobial peptides produced by a halotolerant Bacillus subtilis strain SK.DU.4 isolated from a rhizosphere soil sample", AMB Express, v. 3, n. 1, pp. 1-11, Jan. 2013

[8] PARASZKIEWICZ, K., BERNAT, P., KUŚMIERSKA, A., et al., "Structural identification of lipopeptide biosurfactants produced by Bacillus subtilis strains grown on the media obtained from renewable natural resources", Journal of Environmental Management, v. 209, pp. 65-70, Mar. 2018.

[9] ZHAO, Z., WANG, Q., WANG, K., et al., "Study of the antifungal activity of Bacillus vallismortis ZZ185 in vitro and identification of its antifungal components", Bioresource Technology, v. 101, n. 1, pp. 292-297, Jan. 2010.

[10] BÉCHET, M., CASTÉRA-GUY, J., GUEZ, J.S., et al., "Production of a novel mixture of mycosubtilins by mutants of Bacillus subtilis", Bioresource Technology, v. 145, n. 5, pp. 264-270, Out. 2013.

[11] WEI, W.H., WANG, L.-C., CHEN, W.C., et al., "Production and characterization of fengycin by indigenous Bacillus subtilis F29-3 originating from a potato farm," International Journal of Molecular Sciences, v. 11, n. 11, pp. 4526-4538, Nov. 2010.

[12] PATHAK, K., KEHARIA, H. "Identification of surfactins and iturins produced by potent fungal antagonist, Bacillus subtilis $\mathrm{K} 1$ isolated from aerial roots of banyan (Ficus benghalensis) tree using mass spectrometry”, 3 Biotechology, v. 4, n. 3, pp. 283-295, Jun. 2014.

[13] WU, Y.-S., NGAI, S.-C., GOH, B.-H., et al., "Anticancer activities of surfactin potential application of nanotechnology assisted surfactin delivery”, Frontiers in Pharmacology, v. 8, pp. 1-22, Out. 2017.

[14] SANTOS, V. S. V., SILVEIRA, E., PEREIRA, B.B. "Toxicity and applications of surfactin for health and environmental biotechnology", Journal of Toxicology and Environmental Health, Part B, v. 21, pp. 382399, Jan. 2019.

[15] BHARDWAJ, G., CAMEOTRA, S.S., CHOPRA, H.K. "Biosurfactant from Lysinibacillus chungkukjangi from rice bran oil sludge and potential applications", Journal of Surfactants and Detergents, v. 19, n. 5, pp. 957-965, Set. 2016.

[16] BANAT, I.M., MAKKAR, R.S., CAMEOTRA, S.S. "Potential commercial applications of microbial surfactants”, Applied Microbiology and Biotechnology, v. 53, n. 5, pp. 495-508, Mai. 2000.

[17] SINGH, A., VAN HAMME, J.D., WARD, O.P. "Surfactants in microbiology and biotechnology: Part 2. application aspects”, Biotechnology Advances, v. 25, n. 1, pp. 99-121, Jan.-Feb. 2007.

[18] VAN HAMME, J.D., SINGH, A., WARD, O.P. "Physiological aspects. Part 1 in a series of papers devoted to surfactants in microbiology and biotechnology", Biotechnology Advances, v. 24, n. 6, pp. 604-620, Nov.-Dez. 2006.

[19] GAUR, V.K., BAJAJ, A., REGAR, R.K., et al., "Rhamnolipid from a Lysinibacillus sphaericus strain IITR51 and its potential application for dissolution of hydrophobic pesticides", Bioresource Technology, v. 272, pp. 19-25, Jan. 2019.

[20] SOUSA, M., MELO, V.M.M., RODRIGUES, S. et al., "Screening of biosurfactant-producing Bacillus strains using glycerol from the biodiesel synthesis as main carbon source", Bioprocess and Biosystems Engineering, v. 35, n. 6, pp. 897-906, Ago. 2012.

[21] GARG, M., PRIYANKA, CHATTERJEE, M. "Isolation, characterization and antibacterial effect of biosurfactant from Candida parapsilosis", Biotechnology Reports, v. 18, pp.e00251, Jun. 2018.

[22] SEN, S., BORAH, S.N., BORA, A., et al., "Production, characterization, and antifungal activity of a biosurfactant produced by Rhodotorula babjevae YS3", Microbial Cell Factories, v. 16, n. 1, pp. 1-14, Mai. 2017.

[23] SEKHON RANDHAWA, K., RAHMAN, P.K.S.M. "Rhamnolipid biosurfactants-past, present, and future scenario of global market”, Frontiers in Microbiology, v. 5, pp. 1-7, Set. 2014. 
[24] BEN AYED, H., JEMIL, N., MAALEJ, H., et al., "Enhancement of solubilization and biodegradation of diesel oil by biosurfactant from Bacillus amyloliquefaciens An6”, International Biodeterioration \& Biodegradation, v. 99, pp. 8-14, Abr. 2015.

[25] GASPARIN, F.G.M., MAGRI, A., NEVES, A.F., et al., "Produção de lipase e biossurfactante por isolado de efluente de laticínio”, BBR - Biochemistry Biotechnology Reports, v. 1, n. 1, pp. 28-31, 2012.

[26] VAN SOOLINGEN, D., DE HASS, P.E.W., HERMANS, P.W.M., et al., "Comparison of various repetitive DNA elements as genetic markers for strain differentiation and epidemiology of Mycobacterium tuberculosis”, Journal of Clinical Microbiology, v. 31, n. 8, pp. 1987-1995, Ago. 1993.

[27] NITSCHKE, M., FERRAZ, C., PASTORE, G.M. "Selection of microorganisms for biosurfactant production using agroindustrial wastes", Brazilian Journal of Microbiology, v. 35, n. 1-2, pp. 81-85, Jun. 2004.

[28] ABBASI, H., HAMEDI, M.M., LOTFABAD, T.B., et al., "Biosurfactant-producing bacterium, Pseudomonas aeruginosa MA01 isolated from spoiled apples: Physicochemical and structural characteristics of isolated biosurfactant," Journal of Bioscience Bioengineering, v. 113, n. 2, pp. 211-219, Fev. 2012.

[29] KIM, S.H., LIM, E.J., LEE, S.O. et al., "Purification and characterization of biosurfactants from Nocardia sp. L-417”, Biotechnology Applied Biochemistry, v. 31, n. 3, p. 249, Jun. 2000.

[30] BICCA, F., COLOMBO FLECK, L., ZÁCHIA AYUB, M.A. "Production of biosurfactant by hydrocarbon degrading Rhodococcus ruber and Rhodococcus erythropolis", Revista de Microbiologia, v. 30, pp. 231-236, Set. 1999.

[31] YOUSSEF, N.H., DUNCAN, K.E., NAGLE, D.P., et al., "Comparison of methods to detect biosurfactant production by diverse microorganisms", Journal of Microbiological Methods, v. 56, n. 3, pp. 339-347, Mar. 2004.

[32] DESAI, J.D., BANAT, I.M. "Microbial production of surfactants and their commercial potential", Microbiology and Molecular Biology Reviews, v. 61, n. 1, pp. 47-64, Mar. 1997.

[33] SILVA, M.V.I. "Efeitos do uso do biodiesel sobre propriedades do óleo lubrificante usado em um motor de ignição por compressão", Dissertação MSc., USP, São Carlos, SP, Brasil, 2006.

[34] SILVEIRA, E.L.C., CALAND, L.B., MOURA, C.V.R., et al., "Determinação de contaminantes em óleos lubrificantes usados e em esgotos contaminados por esses lubrificantes”, Química Nova, v. 29, n. 6, pp. 1193-1197, Nov.-Dez. 2006.

[35] SADLER, W.R., TRUDINGER, P.A. "The inhibition of microoganisms by heavy metals", Mineralium Deposita, v. 2, pp. 158-168, Nov. 1967.

[36] THAVASI, R., SUBRAMANYAM NAMBARU, V.R.M., et al., "Biosurfactant Production by Pseudomonas aeruginosa from renewable resources", Indian Journal of Microbiology, v. 51, n. 1, pp. 30-36, Jan. 2011.

[37] DECESARO, A., RIGON, M.R., THOMÉ, A., et al., "Produção de biossurfactantes por microrganismos isolados de solo contaminado com óleo diesel", Química Nova, vol. 36, no. 7, pp. 947-954, 2013.

[38] BENTO, F.M., CAMARGO, F.A.O., OKEKE, B.C., et al., "Diversity of biosurfactant producing microorganisms isolated from soils contaminated with diesel oil”, Microbiological Research, v. 160, n. 3, pp. 249-255, 2005.

[39] MNIF, S., CHAMKHA, M., LABAT, M., et al., "Simultaneous hydrocarbon biodegradation and biosurfactant production by oilfield-selected bacteria," J. Appl. Microbiol., vol. 111, no. 3, pp. 525-536, Set. 2011.

[40] SILVA, S.N.R.L., FARIAS, C.B.B., RUFINO, R.D., et al., "Glycerol as substrate for the production of biosurfactant by Pseudomonas aeruginosa UCP0992”, Colloids and Surfaces B:Biointerfaces, v. 79, n. 1, pp. 174-183, Ago. 2010.

[41] LOPES, M.R.V., AUED-PIMENTEL, S., CARUSO, M.S.F., et al. "Composição de ácidos graxos em óleos e gorduras de fritura”, Revista do Instituto Adolfo Lutz, v. 63, n. 2, pp. 168-176, Jan. 2004.

[42] KOCK, J.L.F., BOTHA, A., BLOCH, J., et al., "Used cooking oil: science tackles a potential health hazard”, South Africa Journal of Science, v. 92, n. 11-12, pp. 513-514, Nov.-Dez.1996.

[43] OLIVEIRA, J.G., GARCIA-CRUZ, C.H. "Properties of a biosurfactant produced by Bacillus pumilus using vinasse and waste frying oil as alternative carbon sources", Brazilian Archives of Biology and Technology, v. 56, n. 1, pp. 155-160, Jan.-Fev. 2013. 
[44] COOPER, D.G., GOLDENBERG, B.G. "Surface-active agents from two Bacillus species" Applied and Environmental Microbiology, v. 53, n. 2, pp. 224-229, Fev. 1987.

[45] ILORI, M.O., AMOBI, C.J., ODOCHA, A.C. "Factors affecting biosurfactant production by oil degrading Aeromonas spp. isolated from a tropical environment”, Chemosphere, v. 61, n. 7, pp. 985-992, Nov. 2005.

[46] KIM, P., OH, D.K., LEE, J.K. KIM, S.Y., et al., "Biological modification of the fatty acid group in an emulsan by supplementing fatty acids under conditions inhibiting fatty acid biosynthesis", Journal of Bioscience and Bioengineering, v. 90, n. 3, pp. 308-312, 2000.

[47] NITSCHKE, M., PASTORE, G.M. "Biossurfactantes: propriedades e aplicações”, Química Nova, v. 25, n. 5, pp. 772-776, 2002.

[48] KITAMOTO, D., IKEGAMI, T., SUZUKI, G.T., et al., "Microbial conversion of n-alkanes into glycolipid biosurfactants, mannosylerythritol lipids, by Pseudozyma (Candida antarctica)", Biotechnology Letters, v. 23, n. 20, pp. 1709-1714, Out. 2001.

[49] TAN, Y.N., LI, Q. "Microbial production of rhamnolipids using sugars as carbon sources", Microbial Cell Factories, v. 17, n. 1, p. 89, Jun. 2018.

[50] PINTO, M.H., MARTINS, R.G., COSTA, J.A.V. "Avaliação cinética da produção de biossurfactantes bacterianos”, Química Nova, v. 32, n. 8, pp. 2104-2108, 2009.

\section{ORCID}

Maria dos Remédios A. Vieira Neta Gabriela Fiori da Silva

Pierre Ferreira do Prado

Mônica Aparecida de Almeida

Iolanda Cristina Silveira Duarte https://orcid.org/0000-0003-0788-1579

https://orcid.org/0000-0001-9803-1267

https://orcid.org/0000-0002-3718-8655

https://orcid.org/0000-0002-0258-3882

https://orcid.org/0000-0002-9141-1010 